\title{
Evaluation and Design Tools for the Reliability of Wind Power Converter System
}

\author{
$\mathrm{Ke} \mathrm{Ma}^{\dagger}$, Dao Zhou*, and Frede Blaabjerg* \\ †,* Department of Energy Technology, Aalborg University, Aalborg, Denmark
}

\begin{abstract}
As a key part in the wind turbine system, the power electronic converter is proven to have high failure rates. At the same time, the failure of the wind power converter is becoming more unacceptable because of the quick growth in capacity, remote locations to reach, and strong impact to the power grid. As a result, the correct assessment of reliable performance for power electronics is a crucial and emerging need; the assessment is essential for design improvement, as well as for the extension of converter lifetime and reduction of energy cost. Unfortunately, there still exists a lack of suitable physic-of-failure based evaluation tools for a reliability assessment in power electronics. In this paper, an advanced tool structure which can acquire various reliability metrics of wind power converter is proposed. The tool is based on failure mechanisms in critical components of the system and mission profiles in wind turbines. Potential methodologies, challenges, and technology trends involved in this tool structure are also discussed. Finally, a simplified version of the tool is demonstrated on a wind power converter based on Double Fed Induction Generator system. With the proposed tool structure, more detailed information of reliability performances in a wind power converter can be obtained before the converter can actually fail in the field and many potential research topics can also be initiated.
\end{abstract}

Key words: Lifetime, Power Electronics, Reliability, Tools, Wind Power

\section{INTRODUCTION}

The fast growth in total installation and individual capacity makes the failure of wind turbines more critical for power grid stability; their repair costs are high because of their remote location which are difficult to access [1]-[3]. In a wind power application, power electronic converters have particularly tough operating conditions; they need to withstand a large amount of power (even up to a few megawatts) with frequent fluctuations of wind speeds, perform a series of complicated functions, and be exposed to harsh environments like temperature swings, dust, vibration, humidity, etc. [1]-[3]. Power electronics tend to be fragile and have become a "bottleneck" of the whole wind turbine system, with respect to reliability [4]-[7]. This problem will significantly increase the cost of energy not only due to the increase in maintenance and repairs, but also because of the reduced energy delivered to the customers.

Today, most of the lifetime information of power

Manuscript received Jan. 25, 2015; accepted May 14, 2015

Recommended for publication by Associate Editor Dong-Myung Lee.

†Corresponding Author: kema@et.aau.dk

Tel: +45-31476850, Aalborg University

* Department of Energy Technology, Aalborg University, Denmark semiconductors have to be collected by a statistics of failed products [5]-[7], and experience-based handbooks are written as a guide to determine the lifetime of different devices and designs. Not surprisingly, this approach has been proven to be untrusted and inaccurate as they are too general and application-independent. Although some device manufacturers have tried to investigate the failure mechanisms and implement accelerating tests to define the lifetime boundaries of power semiconductors under extreme stress levels [10], this approach may not be enough to acquire an accurate lifetime information of power semiconductors for practical use.

As a result, the reliability improving approach for the power electronics is still expensive and time consuming. As shown in Fig. 1(a), a typical flow for improving the reliability of power converters is indicated from the point of view of the whole product life cycle. Given the lack of reliability assessment in the design \& development phase, the design flaws/weakness has to be identified based on failure information or statistics of the field products that have been massively produced and pushed into the market.

As demonstrated in Fig. 1(b), by introducing a reliability assessment tool in the design and development phase, a more 


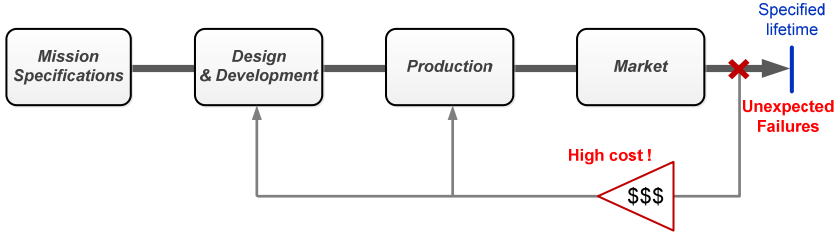

(a) Typical flow in the past.

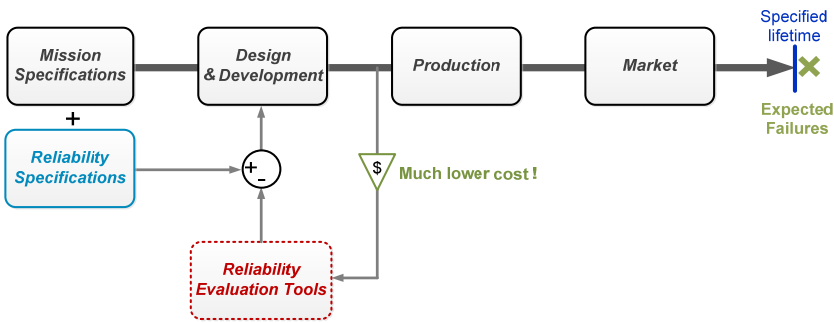

(b) New flow in the future.

Fig. 1. Reliability improvement approach for power electronics products.

promising approach for improving reliability is enabled; the design flaws/weakness can be quickly identified and corrected before the project are put into production and market. Moreover, reliability targets are integrated into the specifications of products at the beginning of the design contributing to a significant cost reduction and shorter development cycle for reliability improvement.

In this paper, an advanced tool structure which can acquire the reliability metrics of wind power converter is proposed, which is based on failure mechanisms in critical components, and mission profiles in the wind turbine system are also considered. The potential methodologies and challenges involved in this tool are also discussed. Finally, the tools are demonstrated on a wind power converter based on a Double Fed Induction Generator system.

\section{GENERAL STRUCTURE AND FLOW TO ACCESS RELIABILITY PERFORMANCES}

The reliability research in power electronics has been carried out for decades. As the state-of-the-art trend, the reliability engineering in power electronics is now moving from a solely statistical approach that has been proven to be unsatisfactory in the automotive industry, to a more physicsbased approach which involves not only the statistics but also the analysis of root cause behind the failures [8]-[10]. In this approach, the correct mapping of a loading profile which can trigger the failure of components (i.e., stress analysis), as well as strength modeling which reflects how much load the components can withstand (i.e., strength tests), are two of the most important activities for reliability assessment.

A promising tool structure is thereby drawn in Fig. 2, which can be categorized into four groups of activities or approaches. In this structure, critical components as well as major failure mechanisms in the converter system are first identified. Based on the involved failure mechanisms in the

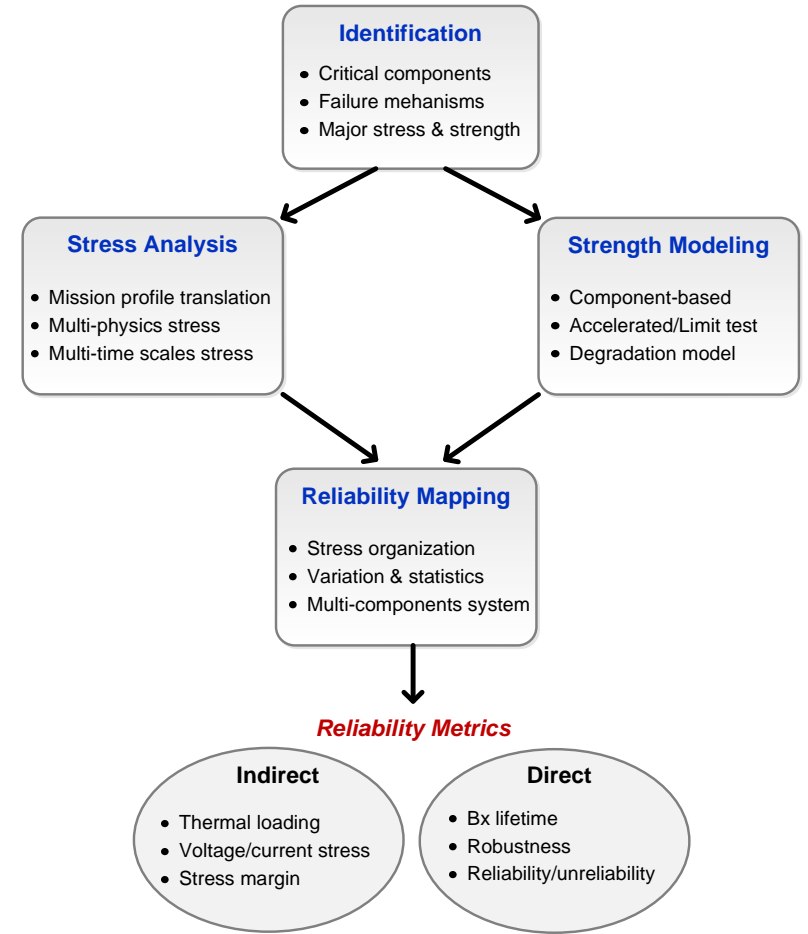

Fig. 2. A proposed tool structure and research activities for evaluating and designing the reliability metrics of power electronics.

critical components, the corresponding stresses and ability of components to withstand stresses (also referred to as strength) are tested and modeled, separately. Finally, a series of algorithms and statistical distributions are introduced to map the stress and strength information of components to the reliability metrics of the whole converter. The reliability metrics may include either direct reliability performances, such as lifetime, robustness, probability of failures changing with time, etc., or indirect reliability-related performances like maximum stress level, stress margin, optimal component rating, etc.

Potential activities and methodologies in the four different activity blocks in Fig. 2 will be briefly discussed and introduced.

\section{A. Identification of Failures}

The target of this block is to identify the most critical components/parts in the system, major failure mechanisms as well as corresponding stress and strength which needs to be clarified. This group of information normally has to rely on investigations and statistics based on failed products/components in the field or various testing results. Many researches have been produced to investigate causes of failure and distributions in power electronics systems [8]-[12].

As an example for wind power application, a well-known failure and down-time investigation based on wind turbine systems are shown in Fig. 3 [5], electrical and control parts dominate the failure in the whole wind turbines. Another investigation found in [6] and [7] indicated that failures and 
unscheduled maintenances for wind power converter may account for $13 \%$ of the entire system. Notice that these statistics were measured 5-8 years ago, and based on a technology developed at least 10 years ago; they are also very application dependent. However, these data do reveal the importance of the reliability problem of power electronics in the wind power conversion technology. Based on statistics regarding failure distributions in power electronics converters [11]-[13], power semiconductors, capacitors and print circuit board (PCB) are three major unreliable components in the converter system.

After the reliability-critical parts and components in the wind power application are identified, failure mechanisms in these components also need clarification. Although the failure mechanisms of power electronics are very complicated and are affected by many factors [8], the thermal cycling (i.e., temperature swings inside or outside devices) is one of the main cause of critical failure in power electronics components [8]-[13]. The internal structure of a typical power semiconductor device is shown in Fig. 4; temperature fluctuation on different materials with mismatched coefficients of thermal expansion (CTE) may cause disconnection at material boundaries, thus, leading to a wearout failure of the devices. Fig. 5 shows an image indicating two types of typical failures inside power semiconductors after certain accelerating thermal cycles; the bond wire lifeoff from the chips in Fig. 5(a) [14], and the cracking of soldering layers in Fig. 5(b) [15]. Similarly, thermal-related failures also exist in the capacitor and PCB, and are also one of the most important killers for these power electronics components [15].

In conclusion, according to extensive researches and investigations [4]-[13], power electronics is one of the most fragile parts in the wind turbine system. On the other hand, power semiconductor, capacitor, and DCB are the most reliability-problematic components in a power electronics converter. The main cause of wear-out failure in these components is thermal cycling at the contacting boundary of two different materials.

After reliability-critical components and major failure mechanisms are identified in the wind power system, the reliability performances can be comprehensively evaluated by analyzing stresses to the components and modelling the ability of the components to withstand these stresses.

\section{B. Stress Analysis}

The target of this group of analysis is to establish models that can translate behaviors or mission profiles of the wind turbine system to stresses in the power electronics components. As one of the major causes of failures in a power electronics converter, the power semiconductor and thermal stress are the main focus of this study. Other failure mechanisms and components can share similar structure and flow of analysis.

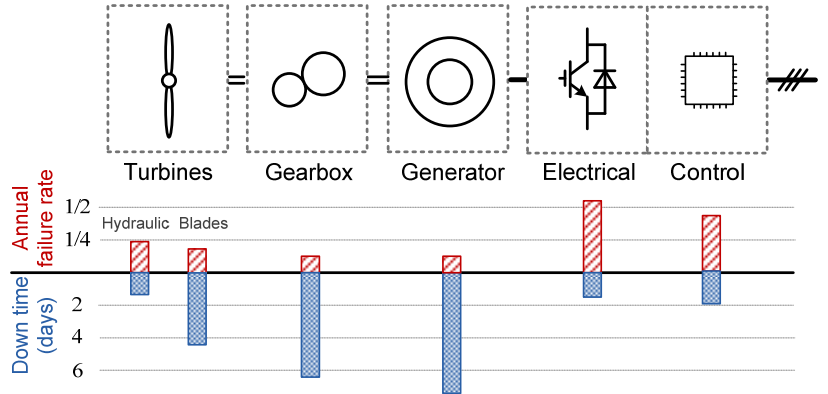

Fig. 3. Failure rate and down time for different parts of wind turbine system [5].

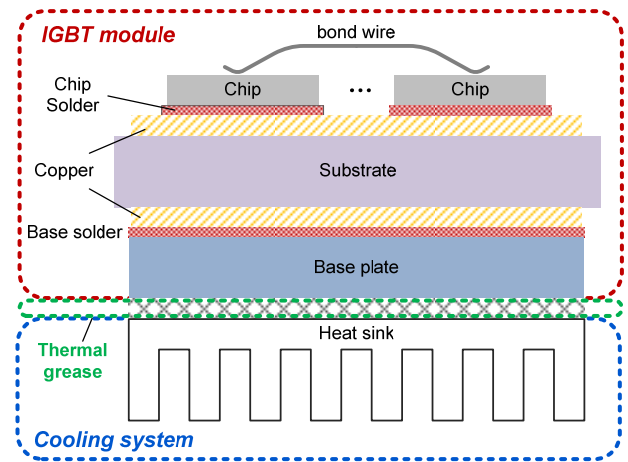

Fig. 4. Structure and material break down for typical power semiconductor devices.

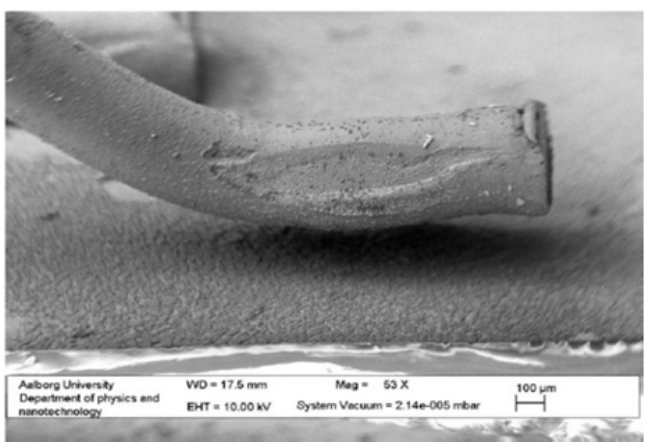

(a) bond wire lift off [14].

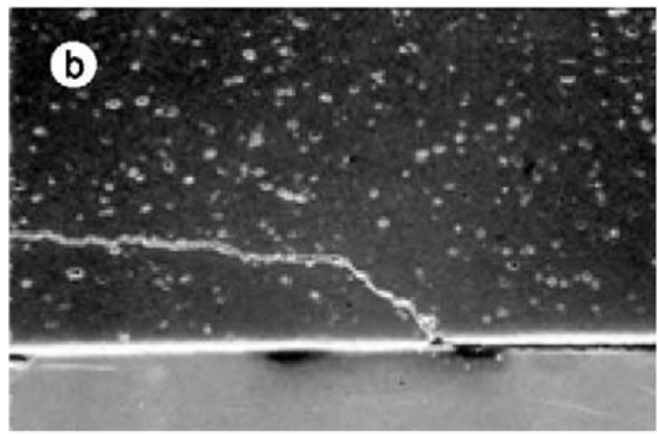

(b) Soldering crack [15].

Fig. 5. Typical failures seen in the power semiconductor devices.

Regarding the wind power system, modelling of complete thermal behaviors in power devices is a very challenging task. Device loadings are closely related to mission profiles of the whole converter system, which includes multi-disciplinary models not only for electrical parts, but also for 


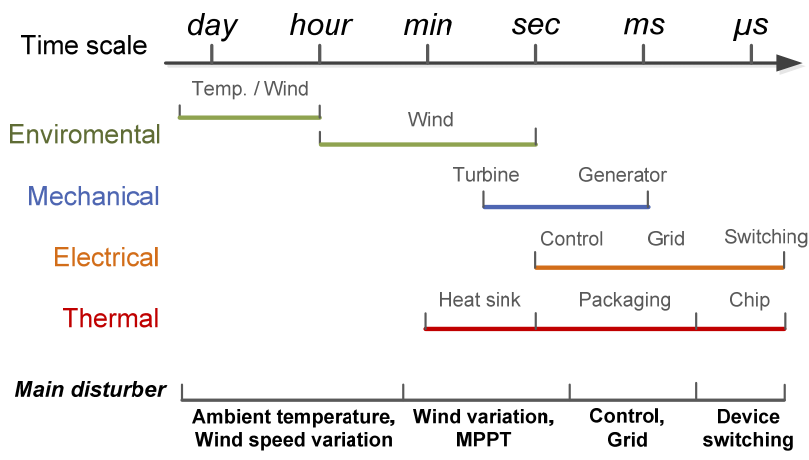

Fig. 6. Multi time-scales disturbances for the thermal behaviors in the wind power converter.

environmental conditions and mechanical parts, as illustrated in Fig. 6. These subsystems have very different time constants ranging from microseconds (i.e., device switching) to years (i.e., ambient temperature changing), thus, making the modelling details a hard decision to make.

An example of different time scales of thermal loading on chips inside the power semiconductor device is shown in Fig. 7 and Fig. 8, respectively. In Fig. 7, simulation results of 2 MW full scale wind power converter with a $1100 \mathrm{~V}$ dc input, $690 \mathrm{~V}$ rms output DC/AC three-phase two-level topology are indicated; and in Fig. 8, the experimental results of $10 \mathrm{~kW}$ power converter with a $600 \mathrm{~V}$ dc input, $380 \mathrm{~V}$ rms output DC/AC three-phase three-level topology are indicated by using infrared camera. More details of the results can be found in [16]. The loading conditions are illustrated under different time scales: first at 1 year span with 3 hours sampling rate and then at 0.2 seconds span with $350 \mathrm{~Hz}$ sampling rate. Behaviors of thermal cycling under different time scales are quite different: the longer term thermal cycling in Fig. 7 is unregulated and mainly caused by variations of converting power depending on wind speeds and turbine/generator operating conditions, while the short term thermal cycling in Fig. 8 is more stable and mainly disturbed by alternating of load current at grid line frequency [16].

Existing methods are not good enough to model the complete thermal behaviors in the power device; either very detailed models are applied but restrained to limited time span and small time steps, or only steady-state conditions are focused with compromised accuracy of certain important thermal dynamics. In order to establish more complete thermal behaviors of power device according to the mission profile of converter, a new approach must be used, as demonstrated in Fig. 9. In the same as lenses with different focus lengths are used in photography, thermal analysis and modelling is separated under several time ranges with different focuses and details of the systems. For wind turbine application, three different model levels can be defined. Each of the model level covers different behaviors of power converter, thereby reflect different causes of thermal

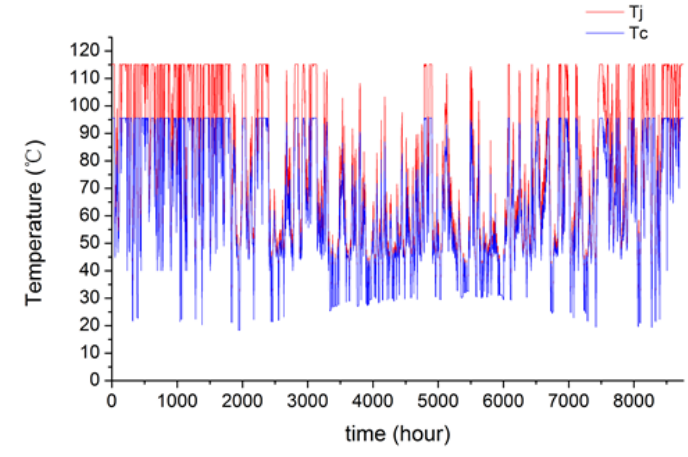

Fig. 7. Simulation results of long term thermal behaviors within 1 year with temperature sampling rate at 3 hours. (Junction temperature $\mathrm{Tj}$ and case temperature $\mathrm{Tc}$ of the IGBT).

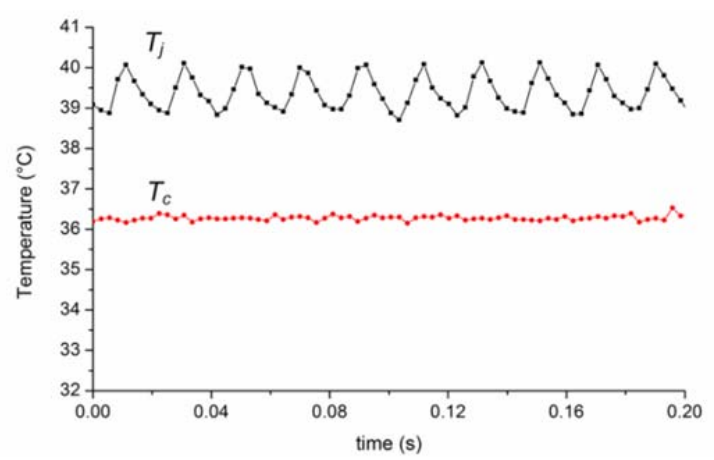

Fig. 8. Experimental results of short term thermal behaviors within 0.2 seconds with temperature sampling rate at $350 \mathrm{~Hz}$. (Junction temperature $\mathrm{Tj}$ and case temperature Tc of the IGBT).

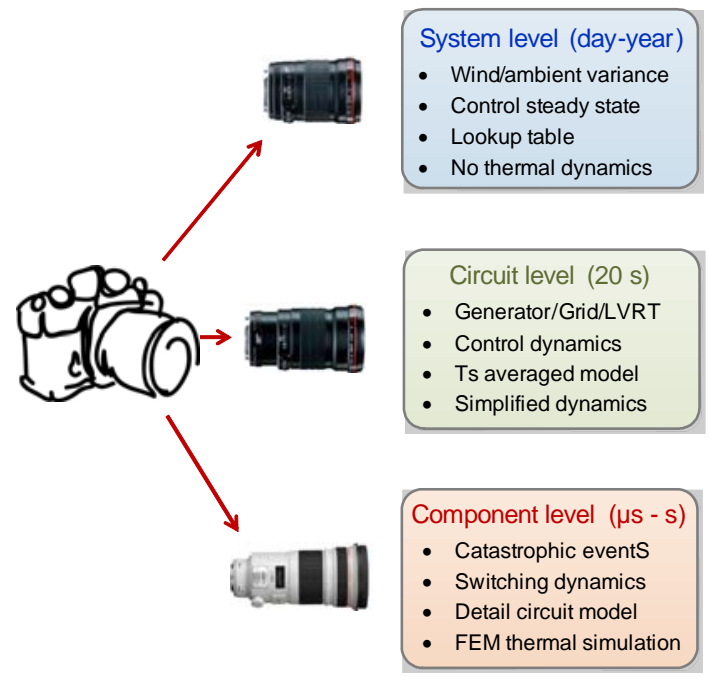

Fig. 9. Multi-time scale thermal behaviors and modeling approach for wind turbine system.

dynamics; the modelling methods used are also different. More details of this multi-time scale thermal modeling approach for power electronics can be found in [17].

Depending on the focus on the disturbance for the thermal cycles, the system can be modelled at various sampling rates, as illustrated in Fig. 9. The 3 hours sampling rate in Fig. 7 is acquired from a real-field recorded data in a wind farm in Denmark. In Fig. 6, the sampling rate mainly targets to reflect 
the disturbance coming from long term environmental changes, such as ambient temperature and day-night wind speed variations. More detailed thermal cycles disturbed by other factors with smaller sampling rates by the appropriate models can also be considered, but are not covered in this paper.

\section{Strength Test and Modelling}

The target of this group of analysis is to test and model the ability of power electronics components to withstand specified stress levels. As one of the major causes of failures in the wind power converter system, thermal cycling and wear-out fatigue in the power semiconductor are the main focus in this paper. There are different ways to quantify the strength of components, unlike the widely used term extreme stress level where the components fail in mechanical or civil engineering, the number of cycles or the time to a certain probable failure is typically used in the field of power electronics.

Normally, the wear-out phenomenon of power semiconductor devices can be indirectly observed by an incensement of on-state conduction voltage or thermal resistance [14]. To facilitate tests of the strength ability of power semiconductors, an approach is to create and repeat intensive thermal cycles to accelerate wear-out progress in the components, and then trace back/predict the wear out progress under normal thermal cycling level.

Basically, two different ways to do the acceleration test include "active power cycling" in which the device is loaded actively with current/voltage for a certain period of time ranging from seconds to hours, and the other is referred as "passive thermal cycling" in which the device is put into a controllable oven and passively loaded with temperate cycles of environment [13]. Many manufacturers of power semiconductors have developed their reliability models based on the above mentioned acceleration test. Fig. 10 shows an example from [10], in which the B10 lifetime (i.e., the number of cycles or time at which the device has $10 \%$ probability of failure) of IGBT modules are indicated under various thermal cycling conditions like cycling amplitude, cycling period, and average mean temperature.

However, in strength testing and modelling process for power semiconductors, none of the existing testing approaches such as "active power cycling" and "passive thermal cycling" can reflect the actual operating conditions of power devices (i.e., the device are normally kept switching at frequency of $\mathrm{kHz}$, and the load current are normally alternated at dozen of $\mathrm{Hz}$ ). These factors will significantly affect thermal behaviors of components and thereby the strength ability. As a result, some researches initialized a more advanced testing setup as shown in Fig. 11 to create more realistic loading conditions of the device and conduct new test as "Mission Profile based thermal cycling". More details of this research can be found in [16].

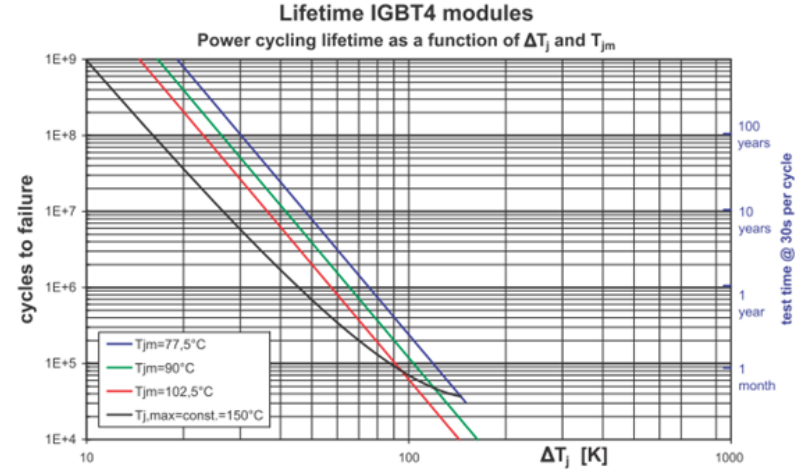

Fig. 10. A typical strength/lifetime model tested by power semiconductor manufacturer [23].

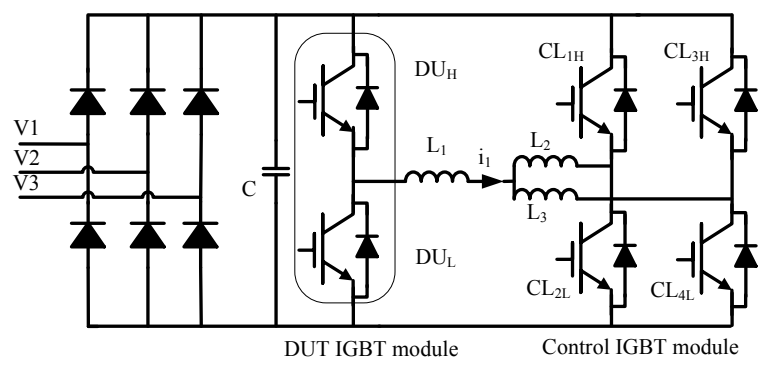

Fig. 11. "Mission profile based thermal cycling" setup for strength test of power semiconductor devices [13].

\section{Reliability Mapping and Estimation}

The target of this group of analysis is to map stress behaviors of the components to the established strength models, and finally, acquire reliability metrics of the components as well as system under the specified mission profiles and component solutions. An example will be demonstrated based on thermal loading in power semiconductor devices in the wind power converter, and the corresponding strength (wear-out B10 lifetime) models tested by manufacturer will be used.

Most thermal loadings of power electronics components in wind power application are unregulated and closely dependent on environmental factors, such as wind speed and ambient temperature. In order to facilitate the use of the strength models, which are normally based on constant and regulated thermal cycles, randomly changed thermal behaviors in power devices cannot be directly used and have to be transferred. A counting method for thermal cycles in a power device called "rainflow counting" [18] is typically used, and a thermal counting result based on 1 year thermal behaviors of a power device in the wind turbine system is shown as an example in Fig. 12 [16], in which randomly changed thermal loadings in devices are translated to cycling amplitude $\mathrm{dT} \mathrm{j}$, mean temperature $\mathrm{Tm}$, and cycling period Tcycle for each count of thermal cycle.

When applying rainflow counted thermal cycles in Fig. 12 to the B10 strength model [23], a total of 1 year consumed lifetime of IGBT module at $10 \%$ probability of failure are shown in Fig. 13, in which three failure mechanisms, such as 


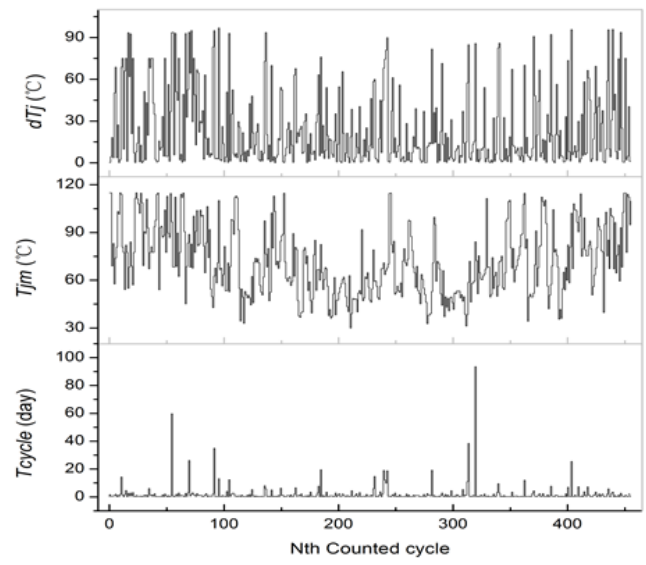

Fig. 12. Rainflow counting result for the 1 year thermal loading of power device shown in Fig. 7.

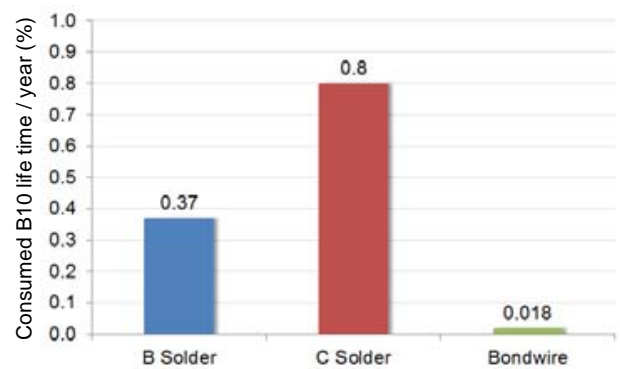

Fig. 13. Consumed life time at $10 \%$ probability of failures of IGBT by counted thermal cycles in Fig. and strength model in Fig. (B solder means Base plate solder, C solder means Chip solder) [16].

the crack of baseplate soldering (B Solder, caused by case temperature cycling), crack of chip soldering (C solder, caused by junction temperature cycling), and bond wire liftoff (bond wire, caused by junction temperature cycling) are shown, respectively.

Furthermore, probability and statistics may add statistical distribution and correlation to acquired stress, strength, and component configurations. This group of discipline will enhance robustness of designed converter and consider severe usage, as well as quality variations of components. This analysis is a future challenge but is an important research direction for power electronics reliability in the wind turbines application.

\section{A CASE STUDY ON A DOUBLE-FED-INDUCTION- GENERATOR-BASED WIND POWER CONVERTER}

This section describes the general procedure to assess the reliability of a power semiconductor device in a doubly-fed induction generator (DFIG) wind power converter. The section is concerned about the thermal stress caused by the fundamental-frequency cycling [19], [20].

\section{A. DFIG Structure}

A typical configuration of the DFIG system is shown in

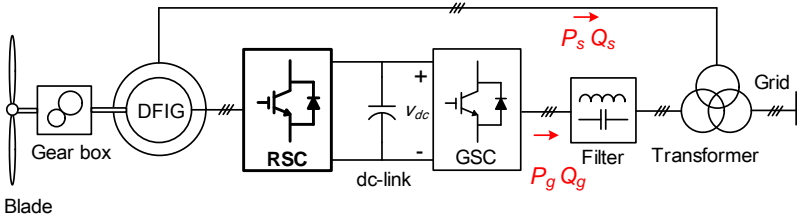

Fig. 14. Typical DFIG configuration in a wind turbine system (GSC: Grid-Side Converter, RSC: Rotor-Side Converter).

Fig. 14. The stator of the generator is directly linked to the grid, while the generator rotor connects to the grid through back-to-back power converters - rotor-side converter (RSC) and grid-side converter (GSC) depending on their positions. The advantage of this concept is the partial rating of the power converter compared to the generator, since only slip power flows through the rotor side of the induction generator. This paper mainly focuses on the lifespan estimation for RSC, as the similar evaluation approach can be extended to GSC.

The dynamic equivalent circuit of DFIG under synchronous rotating frame is shown in [21]. Accordingly, assuming that the rotor values are all transformed to the stator side, the rotor variables can be expressed by the stator variables,

$$
\begin{aligned}
& \left\{\begin{array}{l}
u_{r d}=s\left(\frac{X_{r}}{X_{m}} u_{s d}+\frac{\sigma X_{r} X_{s}}{X_{m}} i_{s q}\right) \\
u_{r q}=-s \frac{\sigma X_{r} X_{s}}{X_{m}} i_{s d}
\end{array}\right. \\
& \left\{\begin{array}{l}
i_{r d}=-\frac{X_{s}}{X_{m}} i_{s d} \\
i_{r q}=-\frac{1}{X_{m}} u_{s d}-\frac{X_{s}}{X_{m}} i_{s q}
\end{array}\right.
\end{aligned}
$$

The expressions of the rotor voltage and the rotor current are calculated in (1) and (2), respectively. $X_{s}, X_{r}$ and $X_{m}$ denote the stator reactance, rotor reactance and magnetizing reactance, respectively, while $s$ and $\sigma$ denote the slip and leakage coefficient of the induction generator.

\section{B. Loss and Thermal Profile}

Loss dissipation of a power switching device mainly consists of conduction loss and switching loss.

As shown in Fig. 14, the loading profile of the active power reference $P_{s}$ from maximum power point traction (MPPT) and the reactive power reference $Q_{s}$ required by the grid codes can be translated to relevant variables used for loss calculation - the rotor voltage $u_{r}$, rotor current $i_{r}$, displacement angle $\varphi_{r}$ and rotor current frequency $f_{r}$.

With respect to conduction loss, according to the calculated duty cycle $d$ using traditional space vector modulation (SVM), the rotor current and the frequency of the rotor current, as well as on-state voltage drop information from the manufacturer datasheet, the conduction loss can be calculated by accumulation of every switching pattern within the whole fundamental period of the loading current. Similarly, the information of rotor current and rotor frequency, together with the switching energy curve from the manufacturer 


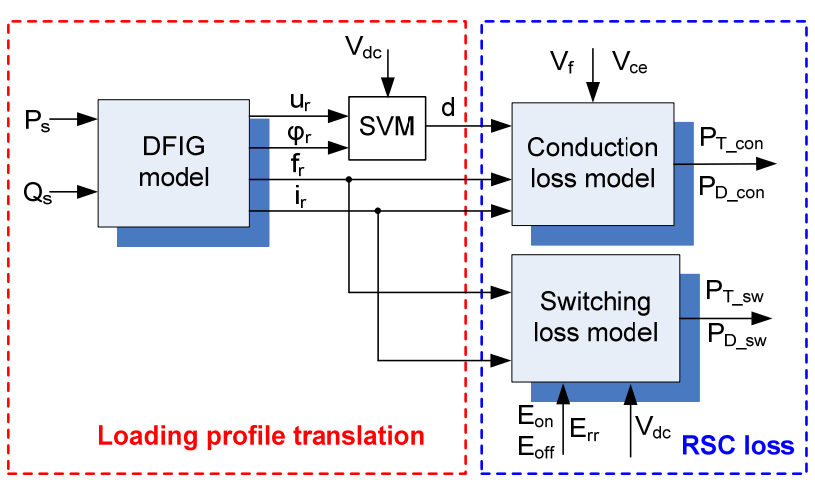

Fig. 15. Framework of loss calculation for the Rotor-Side Converter (RSC).

datasheet, are used to compute for switching loss, which is considered proportional to dc-link voltage $V_{d c}$.

Thermal impedance decides the junction temperature of a power device, which usually consists of the power module itself (from junction to baseplate or case) and thermal integrate material (TIM), as well as the cooling method. Generally, the thermal time constant of a typical air cooled system is from dozens to hundreds of seconds for MW-level power converter, while the maximum thermal time constant of the power module itself is hundreds of milliseconds. On the other hand, the maximum fundamental period of RSC output current is only hundreds of milliseconds, which implies that the thermal cycling caused by the air cooling can almost be neglected [22]. As a result, for the steady-state thermal cycle, the thermal model of the cooling method will only affect the mean junction temperature, but will not disturb the junction temperature fluctuation.

The mean junction temperature $T_{j m}$ and the junction temperature fluctuation $d T_{j}$ are normally regarded as the two most important reliability assessment indicators, and the formula to calculate them are [22], [23],

$$
\begin{aligned}
& T_{j m_{-} T / D}=P \cdot \sum_{i=1}^{4} R_{t h j c_{-} T / D(i)}+P \cdot \sum_{j=1}^{3} R_{t h c a_{-}(j)}+T_{a} \\
& d T_{j_{-} T / D}=2 P \cdot \sum_{i=1}^{4} R_{t h j c_{-} T / D(i)} \cdot \frac{\left(1-e^{-\frac{t_{o n}}{\tau_{l i j c_{-} T / D(i)}}}\right)^{2}}{1-e^{-\frac{t_{p}}{\tau_{t h j c_{C} T / D(i)}}}}
\end{aligned}
$$

In (3), $R_{t h j c}$ is the thermal resistance from the junction to case of the power module, $R_{\text {thca }}$ is the thermal resistance of the air cooling, in which subscripts $T$ and $D$ denote IGBT and the freewheeling diode, whereas subscripts $i$ and $j$ denote four-layer and three-layer Foster structure for power module and air cooling, respectively. $P$ is the power loss of each power semiconductor, and $T_{a}$ is the ambient temperature. In (4), $t_{o n}$ denotes the on-state time within each fundamental period of the current at the steady-state operation, $t_{p}$ denotes the fundamental period of the current, and $\tau$ denotes the thermal time constant of each Foster layer.

\section{Lifetime Estimation with Various Wind Classes}

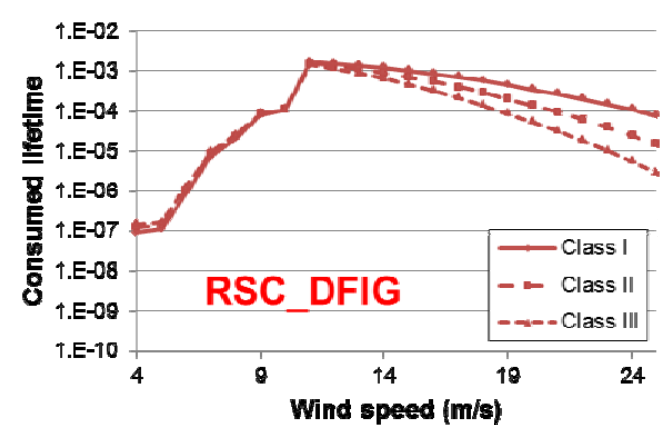

(a) Consumed lifetime per year.

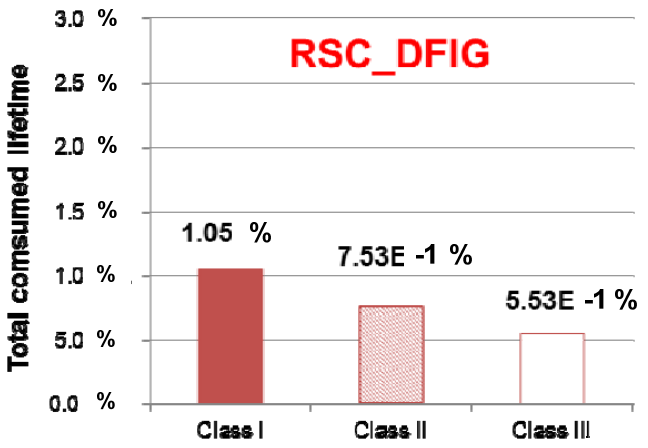

(b) Total consumed lifetime (in the unit of \%).

Fig. 16. Lifetime estimation of the Rotor-side Converter.

The calculation procedure of the RSC lifespan is shown in Fig. 16. Various annual wind profiles are taken into consideration, where Class I, Class II and Class III indicate the annual average wind speed of $10 \mathrm{~m} / \mathrm{s}, 8.5 \mathrm{~m} / \mathrm{s}$ and $7.5 \mathrm{~m} / \mathrm{s}$, respectively [24]. Afterward, the annual wind distribution is decomposed into several typical wind speeds from the cut-in until the cut-off speed with the increment of $1 \mathrm{~m} / \mathrm{s}$. Using the mentioned loss and thermal calculation, the power cycles to failure $N_{f}$ can be roughly estimated based on the CoffinMansion model, in which the mean junction temperature, junction temperature swing and the on-state time $t_{o n}$ are considered [26], [27]. Then, the consumed lifetime per year (CL) for each averaged wind speed $n$ can be obtained by:

$$
C L_{n}=\frac{N_{\mathrm{n}}}{N_{f_{-} n}}=\frac{t_{n} \cdot f_{r_{-} n}}{N_{f_{-} n}}=\frac{D_{n} \cdot 365 \cdot 24 \cdot 3600 \cdot f_{r_{-} n}}{N_{f_{-} n}} \text { (5) }
$$

where $C L_{n}$ means how many percentage experienced thermal cycles at wind speed of $n$ have consumed the total lifetime of the device. $N_{f_{n}}$ means the number of cycles to failures or total lifetime of device under a certain stress level, and it can be mapped from a lifetime model shown in Fig. 10. $N_{n}$ and $t_{n}$ represent experienced number of thermal cycles and total time, respectively, at wind speed of n. $D_{n}$ denotes the percentage of time for each wind speed accounting for the total time of one year, and $f_{r_{-} n}$ denotes the frequency of rotor current under wind speed of $n$.

Assuming that the fatigue damage is linearly accumulated [26], [27], the total consumed lifetime (TCL) can then be estimated by the decomposition of wind speed. 


$$
T C L=\sum_{n=4}^{25} C L_{n}
$$

As shown in Fig. 16, the lifetime of RSC is estimated with various annual wind profiles. The higher wind class results in lower lifetime of RSC with the same design criteria. For instance, the total consumed lifetime reduces from 5.53E-3 of the Class III to $1.05 \mathrm{E}-2$ of the Class I, which implies that lifetime becomes almost one half.

\section{CONCLUSION}

An advanced tool structure which can acquire the reliability metrics of wind power converter is proposed. The tool is based on stress and strength analysis in the critical components of the system, and mission profiles in the wind turbines are also taken into account. The potential methodologies, challenges and technology trends involved in this tool structure are also discussed. With the proposed tools structure, more detailed information of the reliability performances in wind power converter can be obtained before the converter actually fails in the field, and many potential research topics can be also enabled.

\section{REFERENCES}

[1] F. Blaabjerg, M. Liserre, and K. Ma, "Power electronics converters for wind turbine systems," IEEE Trans. Ind. Appl., Vol. 48, No. 2, pp. 708-719, Mar./Apr. 2012.

[2] F. Blaabjerg and K. Ma, "Future on power electronics for wind turbine systems," IEEE J. Emerg. Sel. Topics Power Electron., Vol. 1, No. 3, pp. 139-152, Sep. 2013.

[3] Z. Chen, J. M. Guerrero, and F. Blaabjerg, "A Review of the state of the art of power electronics for wind turbines," IEEE Trans. Power Electron., Vol. 24, No. 8, pp. 18591875, Aug. 2009.

[4] Reliawind, Report on wind turbine reliability profiles - field data reliability analysis, EU $7^{\text {th }}$ Framework Programme, 2011.

[5] B. Hahn, M. Durstewitz, and K. Rohrig "Reliability of wind turbines - Experience of 15 years with 1500 WTs," Wind Energy, Spinger, Berlin, 2007.

[6] S. Faulstich, P. Lyding, B. Hahn, and P. Tavner "Reliability of offshore turbines-identifying the risk by onshore experience," in Proc. of European Offshore Wind, 2009.

[7] L. M. Moore and H. N. Post, "Five years of operating experience at a large, utility-scale photovoltaic generating plant," Journal of Prog. Photovolt: Res. Appl. Vol. 16, No. 3, pp. 249-259, 2008

[8] E. Wolfgang, L. Amigues, N. Seliger, and G. Lugert, "Building-in reliability into power electronics systems," The World of Electronic Packaging and System Integration, pp. 246-252, 2005.

[9] D. Hirschmann, D. Tissen, S. Schroder, and R.W. De Doncker, "Inverter design for hybrid electrical vehicles considering mission profiles," IEEE Conference on Vehicle Power and Propulsion, 7-9, pp. 1-6, 2005.

[10] C. Busca, R. Teodorescu, F. Blaabjerg, S. Munk-Nielsen, L. Helle, T. Abeyasekera, and P. Rodriguez, "An overview of the reliability prediction related aspects of high power IGBTs in wind power applications," Microelectronics Reliability, Vol. 51, No. 9-11, pp. 1903-1907, Sep./Nov. 2011.

[11] E. Wolfgang, "Examples for failures in power electronics systems," presented at ECPE Tutorial on Reliability of Power Electronic Systems, 2007.

[12] S. Yang, A. T. Bryant, P. A. Mawby, D. Xiang, L. Ran, and P. Tavner, "An industry-based survey of reliability in power electronic converters," IEEE Trans. Ind. Appl., Vol. 47, No. 3, pp. 1441-1451, May/Jun. 2011

[13] J. Due, S. Munk-Nielsen, and R. Nielsen, "Lifetime investigation of high power IGBT modules," in Proc. of EPE'2011 - Birmingham, 2011.

[14] S. Beczkowski, P. Ghimire, A. R. de Vega, S. MunkNielsen, B. Rannestad, and P. Thøgersen, "Online $V_{\text {ce }}$ measurement method for wear-out monitoring of high power IGBT modules," in Proc. EPE 2013, pp. 1-7, 2013.

[15] M. Ciappa "Selected failure mechanisms of modern power modules," Microelectronics Reliability, Vol. 42, No. 4-5, pp. 653-667, Apr./May 2002.

[16] K. Ma, M. Liserre, F. Blaabjerg, and T. Kerekes, "Thermal loading and lifetime estimation for power device considering mission profiles in wind power converter," IEEE Trans. Power Electron., Vol. 30, No. 2, pp. 590-602, Feb. 2015.

[17] K. Ma, Y. Yang, and F. Blaabjerg, "Transient modelling of loss and thermal dynamics in power semiconductor devices," in Proc. of ECCE 2014, 2014.

[18] A. Niesłony, "Determination of Fragments of Multiaxial Service Loading Strongly Influencing the Fatigue of Machine Components," Mechanical Systems and Signal Processing, Vol. 23, No.8, pp. 2712-2721, Nov. 2009.

[19] D. Weiss and H. G. Eckel, "Fundamental frequency and mission profile wearout of IGBT in DFIG converters for windpower," in Proc. of EPE 13, pp. 1-6, 2013.

[20] D. Zhou, F. Blaabjerg, M. Lau, and M. Tonnes, "Thermal cycling overview of multi-megawatt two-level wind power converter at full grid code operation," IEEJ J. Ind. Appl., Vol. 2, No. 4, pp. 173-182, Jul. 2013.

[21] G. Abad, J. Lopez, M. Rodriguez, L. Marroyo, and G. Iwanski, Doubly Fed Induction Machine-Modeling and Control for Wind Energy Generation, Piscataway, NJ: IEEE Press, 2011.

[22] D. Zhou, F. Blaabjerg, M. Lau, and M. Tonnes, "Thermal profile analysis of doubly-fed induction generator based wind power converter with air and liquid cooling methods," in Proc. of EPE 13, pp.1-10, 2013.

[23] A. Wintrich, U. Nicolai, and T. Reimann, "Semikron Application Manual," 2011.

[24] Wind turbines - part I: design requirements", IEC 61400-1, 3rd edition.

[25] U. Scheuermann and R. Schmidt, "A new lifetime model for advanced power modules with sintered chips and optimized Al wire bonds," in Proc. of PCIM 2013, pp. 810813, 2013.

[26] ABB Application Note, Load-Cycling Capability of HiPaks, 2004.

[27] M. A. Miner, "Cumulative damage in fatigue," Journal of Applied Mechanics, No. 12, A159-A164, 1945. 


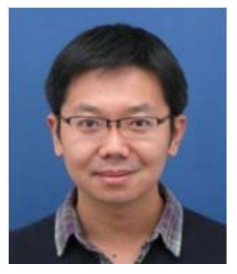

Ke Ma (S'09-M'11) received his B.Sc. and M.Sc. degrees in electrical engineering from the Zhejiang University, China in 2007 and 2010, respectively. He received his Ph.D. degree from the Aalborg University, Denmark in 2013, where he became a Postdoc in 2013 and became an Assistant Professor in 2014. His current research interests include the power electronics and reliability in the application of renewable energy systems. Dr. Ma received the Excellent Young Wind Doctor Award 2014 by European Academy of Wind Energy, and he was the receiver of a few IEEE prized paper awards. Right now he is serving as an Associate Editor on IEEE Transaction on Industry Applications.

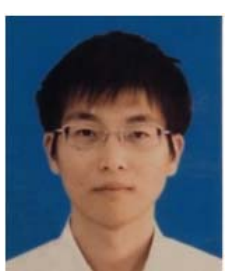

Dao Zhou (S'12) received his B.Sc. in electrical engineering from Beijing Jiaotong University, Beijing, China, in 2007, and M. Sc. in power electronics from Zhejiang University, Hangzhou, China, in 2010. He received his Ph.D degree in the Department of Energy Technology, Aalborg University, Denmark, in 2014, where he is currently working as a Postdoc. His research interests include power electronics converters and their application and reliability in wind power generation systems.

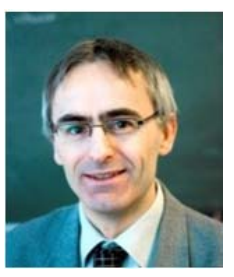

Frede Blaabjerg (S'86-M'88-SM'97-F'03) was with ABB-Scandia, Randers, Denmark, from 1987 to 1988. From 1988 to 1992, he was a Ph.D. student in Aalborg University, Aalborg, Denmark. He became an Assistant Professor in 1992, an Associate Professor in 1996, and a full professor in power electronics and drives in 1998. His current research interests include power electronics and its applications such as in wind turbines, PV systems, reliability, harmonics, and adjustable speed drives. He has received 15 IEEE Prize Paper Awards, the IEEE PELS Distinguished Service Award in 2009, the EPE-PEMC Council Award in 2010, the IEEE William E. Newell Power Electronics Award 2014 and the Villum Kann Rasmussen Research Award 2014. He was an Editor-in-Chief of the IEEE TRANSACTIONS ON POWER ELECTRONICS from 2006 to 2012. He was a distinguished lecturer for the IEEE Power Electronics Society from 2005 to 2007 and for the IEEE Industry Applications Society from 2010 to 2011. 